\title{
Statistical Study of Nine Months Distribution of Solar Flares
}

\author{
Z. S. Hamidi ${ }^{1, *}$, N. N. M. Shariff ${ }^{2}$, C. Monstein ${ }^{3}$ \\ ${ }^{1}$ School of Physics and Material Sciences, Faculty of Sciences, MARA University of Technology, \\ 40450, Shah Alam, Selangor, Malaysia \\ ${ }^{2}$ Academy of Contemporary Islamic Studies (ACIS), MARA University of Technology, \\ 40450, Shah Alam, Selangor, Malaysia \\ ${ }^{3}$ Institute of Astronomy, Wolfgang-Pauli-Strasse 27, Building HIT, Floor J, \\ $\mathrm{CH}-8093$ Zurich, Switzerland \\ *E-mail address: zetysh@salam.uitm.edu.my
}

\begin{abstract}
Solar flare is one of the solar activities that take place in the outermost layer of the corona. Solar flares can heat the material to several million degrees in just a few minutes and at the same time they release the numerous amount of energy. It is believed that a change of magnetic field lines potentially creates the solar flares. The objectives of the study are to identify and compare the types of solar flares (in X-Ray) region and to improve understanding of solar flares. Data are taken from the NOAA website, from the United States Department of Commerce, NOAA, Space Weather Prediction Center (SPWC). Solar radio flux readings were merged together with the three classes and a total of nine graphs were plotted. In illustrating the relationship of solar radio flux and solar flares, it can be explained by studying the range values of flux corresponding to flares values. From this case study, it was found that the minimum value of solar radio flux in order for the flares to occur is equivalent $68 \mathrm{x}$ $10^{-22} \mathrm{Wm}^{-2} \mathrm{~Hz}^{-1}$. Thus, whenever the values of solar radio flux are high, there should be a higher number of flares produced by the sun. The overall range of solar radio flux recorded in this study ranging from $68 \times 10^{-22} \mathrm{Wm}^{-2} \mathrm{~Hz}^{-1}$ to $96 \times 10^{-22} \mathrm{Wm}^{-2} \mathrm{~Hz}^{-1}$. Observing and collecting data from the Sun and develop our very own new prediction methods will leads the accuracy of the prediction of the behavior of the Sun more precisely.
\end{abstract}

Keywords: Sun; solar eclipse; solar radio; burst, type III; e-CALLISTO

\section{INTRODUCTION}

The Sun is the most prominent feature in our solar system. It is the largest object and contains approximately $98 \%$ of the total solar system mass. It can be classified into seven types of layers which are (i) Inner Core (ii) Radiative Zone (iii) Convection Zone (iv) Subsurface Flows (v) Photosphere (vi) Chromosphere and (vii) Corona. At ground based observation, the Sun activities can be studied by examining the effects throughout both optical telescope and also radio telescope . 
Solar flare is one of the solar activities that take place in the outermost layer of the corona. Solar flares can heat the material to several million degrees in just a few minutes and at the same time they release the numerous amount of energy [1]. The energy is almost equivalent to megatons of TNT [2]. Solar flares are the result that arises from the sunspot and they are associated with the changes of the magnetic field [3]. During that time, a large number of electrons are accelerated with very high temperature $(\sim 10-20 \mathrm{MK})$. Differences of source size, ejections of plasma blobs into interplanetary space, and blast waves [4]. This explosion can be a combination of Bremsstrahlung which can be detected in the X-ray region and non- thermal electron which could be observed in radio region [5]. The impulsiveness of the flare energy release is possibly triggered by a sudden change in resistivity by highfrequency wave turbulence and is probably related to the capability of particle acceleration [6].

It is believed that a change of magnetic field lines potentially creates the solar flares. some active-region loops become brilliant soft X-ray emitters, outshining the rest of the corona. As the Sun rotates around its axis, the magnetic field lines threaded to the Sun also follow the same rotation. But when there is variation in the Sun velocity, the magnetic field lines sometimes gets twisted up and become more complicated in their shape. When this situation happens, the magnetic field lines sometimes become too complicated in shape as they tend to overlapping with each other, and in the end they get twisted up and cut loose from the original lines and set free as solar flares.

It has a dynamism in terms of structure and can be divided into a few sub-types. This burst has a dynamical structure and very dominant in the meter region [7]. It can also associate with Coronal Mass Ejections (CMEs) event [8]. The objectives of the study are to identify and compare the types of solar flares (in X-Ray) region and to improve understanding of solar flares. In this work, we concentrate the statistical data from January to September 2010 based on different classification. By doing this study, better understanding towards solar flares can be achieved. It is crucial to relate the possible results which are associated with the solar flares based on it classification. Thus, we need to realize that we are one of the closet regions on earth that will be among the first to experience solar flares effects when it reach the earth's surface.

\section{EXPERIMENTAL SETUP AND OBSERVATION}

Data are taken from the NOAA website, from the United States Department of Commerce, NOAA, Space Weather Prediction Center (SPWC). Daily observation and analyzation were made throughout the period of nine months. Below are the explanations on the theoretical analysis that were used throughout this study. Features that were selected from the raw data were only date, the solar radio flux and flares corresponds to C, M and X Class. Solar radio flux readings were merged together with the three classes and a total of nine graphs were plotted. Analyzation parts were included in the results and discussion section in the next section.

Observation of solar flare and CMEs in the radio region in Malaysia has started since 2005 [9]. In this study, we used the Compound Astronomical Low-frequency, Low-cost Instrument for Spectroscopy Transportable Observatories (CALLIISTO) system is used in obtaining a dynamic spectrum of solar radio burst data. We also used our own Log Periodic Dipole Antenna (LPDA). The system was mounted at the National Space Centre (ANGKASA) building at Sg. Lang, Banting, Selangor located at (N 02 ${ }^{\circ} 49.488^{\prime} \mathrm{E} 101^{\circ}$ 
36.168') covered from 45-870 MHz [10]. At first stage, a preliminary analysis of RFI has been done in the previous work [11].

Some modification, calibration process and basic testing of the antenna has been done in order to improve the quality of the system [12-16]. However, to avoid the interference signal, we focused the range of $150 \mathrm{MHz}$ till $350 \mathrm{MHz}[17,18]$. So far, this region is the best region with minimum interference at our site that might affect the solar radio burst data [19]. The data from 150-400 MHz region seems is selected seems this is the finest range with lowest of Radio Frequency Interference (RFI) [20]. An observation of 12 hours solar monitoring is done routinely [21-39].

\section{RESULTS AND ANALYSIS}

In this section, we will highlight the overall results and discuss a total of nine graphs complete with the analysis were discussed. These graphs were plotted separately starting from January up through September. Figure 1-9 illustrate the distribution of different class of solar flare from January to September 2010.

A total of 143 of solar flares were observed during this period. Class $\mathrm{C}$ flares recorded the highest number which is 124 flares during the period of this study followed by class $\mathrm{M}$ flares which is 19 and lastly class X flares which is 0 . The average number of solar flares recorded in January, February, March, April, May, June, July, August and September is 11, $18,3,0,3,4,3,3$ and 2 respectively. Between all the months, the Sun was found to be most active in the month of February by producing a total of 53 flares and least active in the month of April by producing only 1 flare. If the flare is the X Class flare, the possibilities to create CMEs is higher as CMEs is associated with X Class solar flare wherein the energy being released is very high in term of mass flow.

In illustrating the relationship of solar radio flux and solar flares, it can be explained by studying the range values of flux corresponding to flares values. From this case study, it was found that the minimum value of solar radio flux in order for the flares to occur is equivalent $68 \times 10^{-22} \mathrm{Wm}^{-2} \mathrm{~Hz}^{-1}$. Thus, whenever the values of solar radio flux are high, there should be a higher number of flares produced by the sun. The overall range of solar radio flux recorded in this study ranging from $68 \times 10^{-22} \mathrm{Wm}^{-2} \mathrm{~Hz}^{-1}$ to $96 \times 10^{-22} \mathrm{Wm}^{-2} \mathrm{~Hz}^{-1}$. The highest peak of solar radio flux was observed to be in the month of February where the sun was found to be most active previously. This condition is in agreement with the relation as stated above and also supports that solar radio flux is closely related to flare production.

As there was no class $\mathrm{X}$ reported at all in this study, we can assume that there are no major effects that happened on earth and outer space such as CMEs and solar storms. These kinds of phenomena resulting from powerful solar flares corresponding to class X flares can actually affect people, but the possibilities are somehow restricted to several conditions. The earth's atmosphere protects us as it absorbs the majority of the effects of solar storms. However, for astronauts solar storms can be dangerous, as they are exposed to protons and plasma that can cause radiation poisoning [20]. Results from this study showed that we are somehow still safe from these kinds of radiations. But for future purposes, we can predict the behavior of solar flares as it can benefit us by preparing preventative measurements in order to reduce possible damage. 


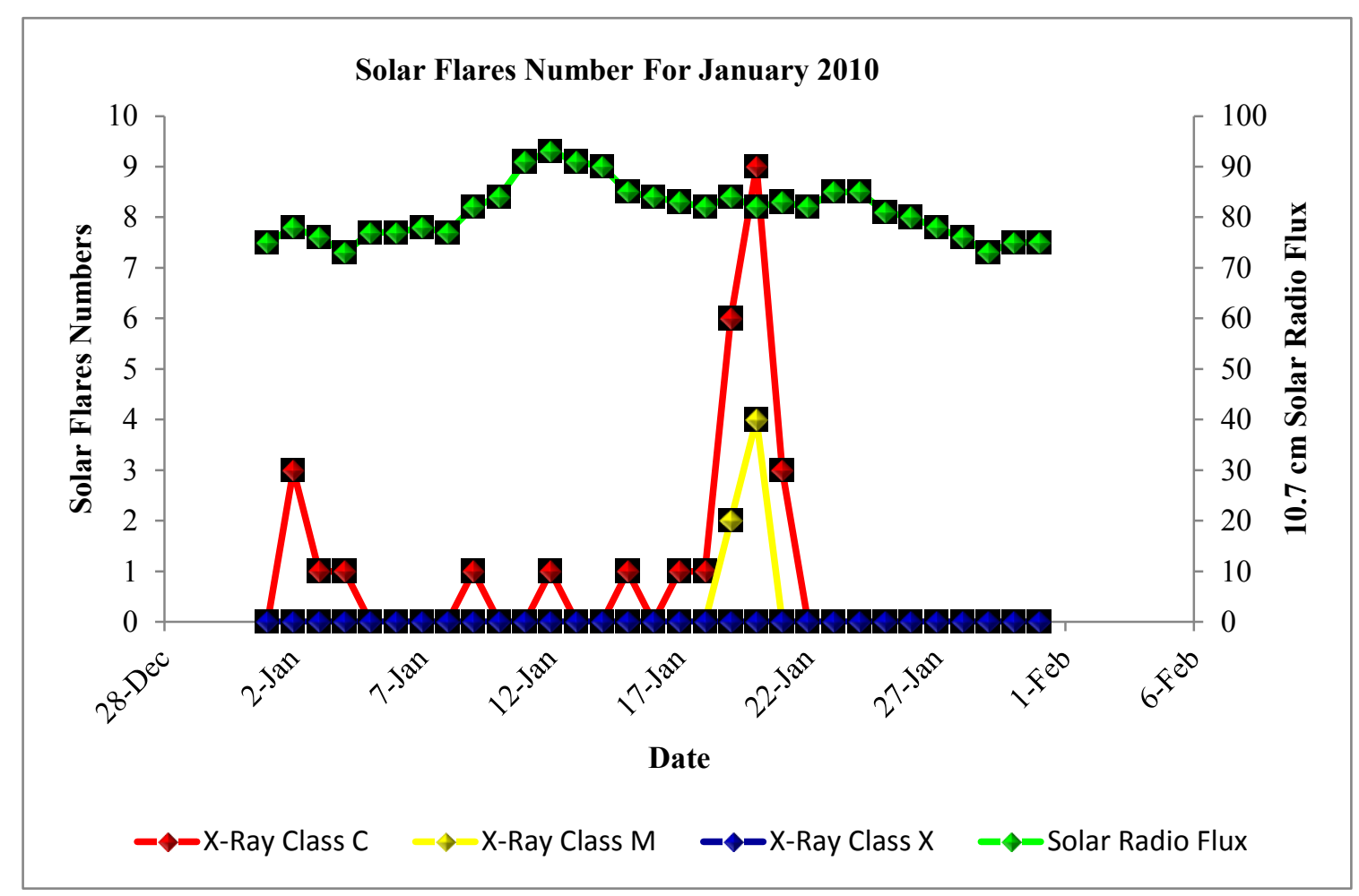

Figure 1. Solar flares numbers in January.

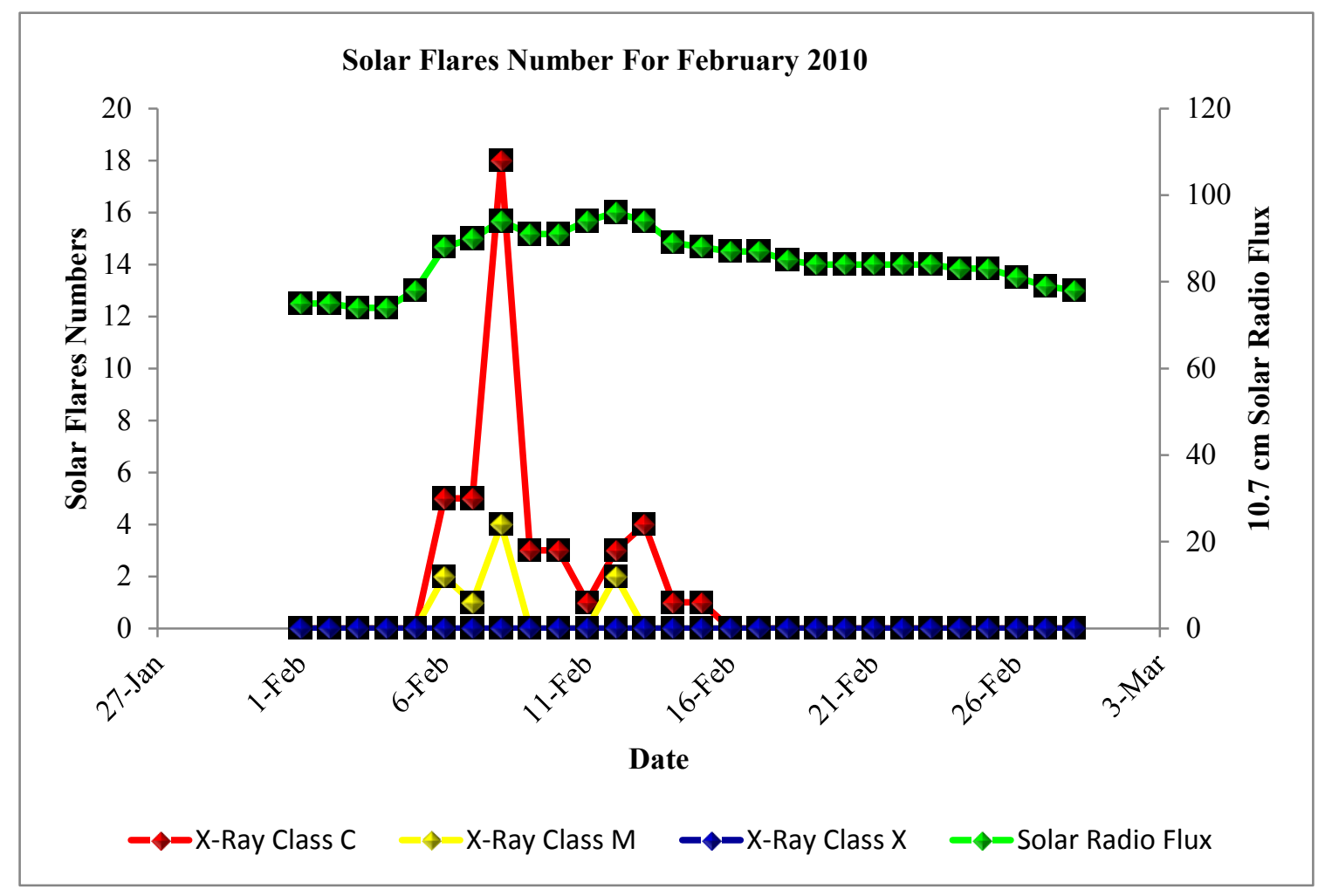

Figure 2. Solar flares numbers in February. 


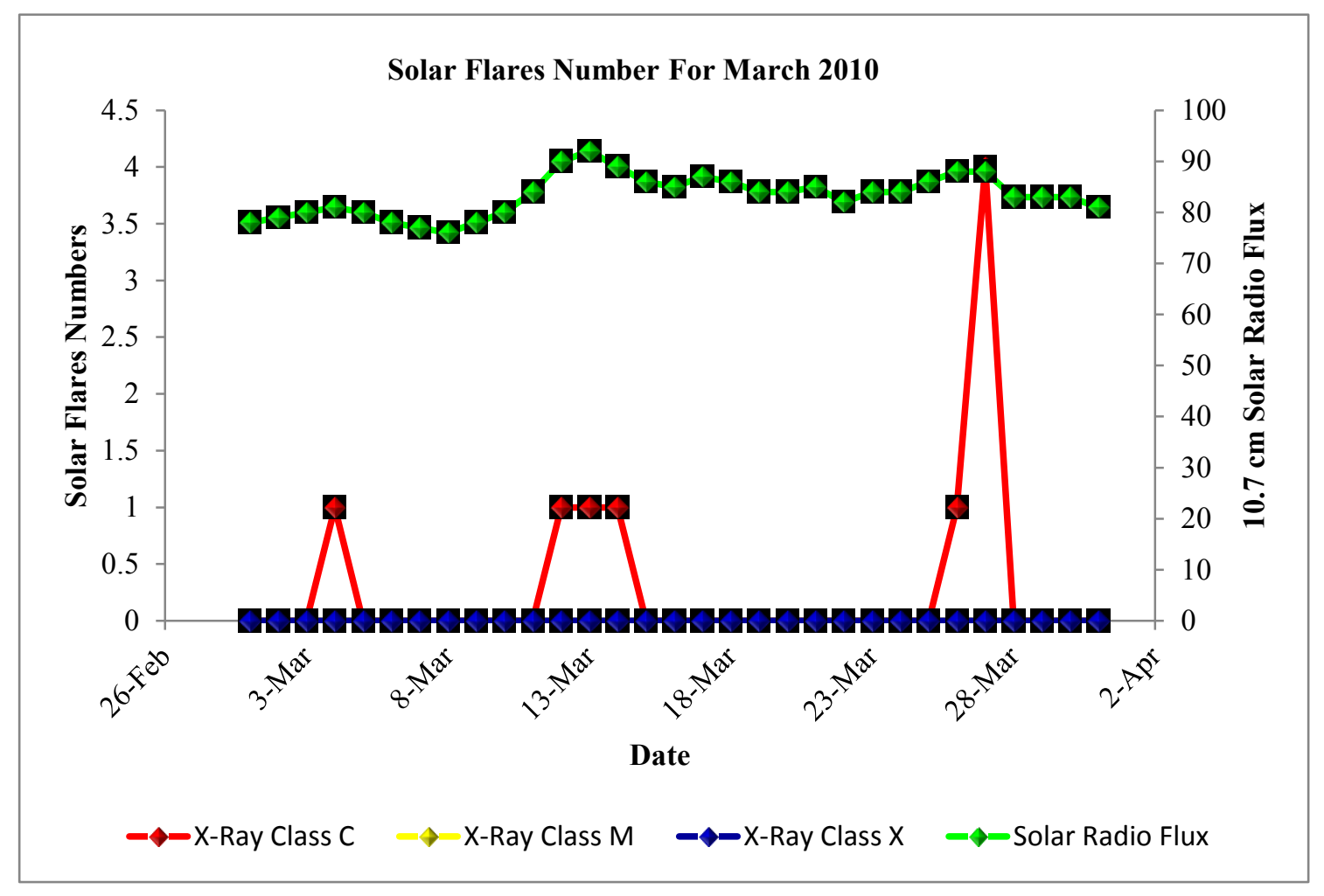

Figure 3. Solar flares numbers in March.

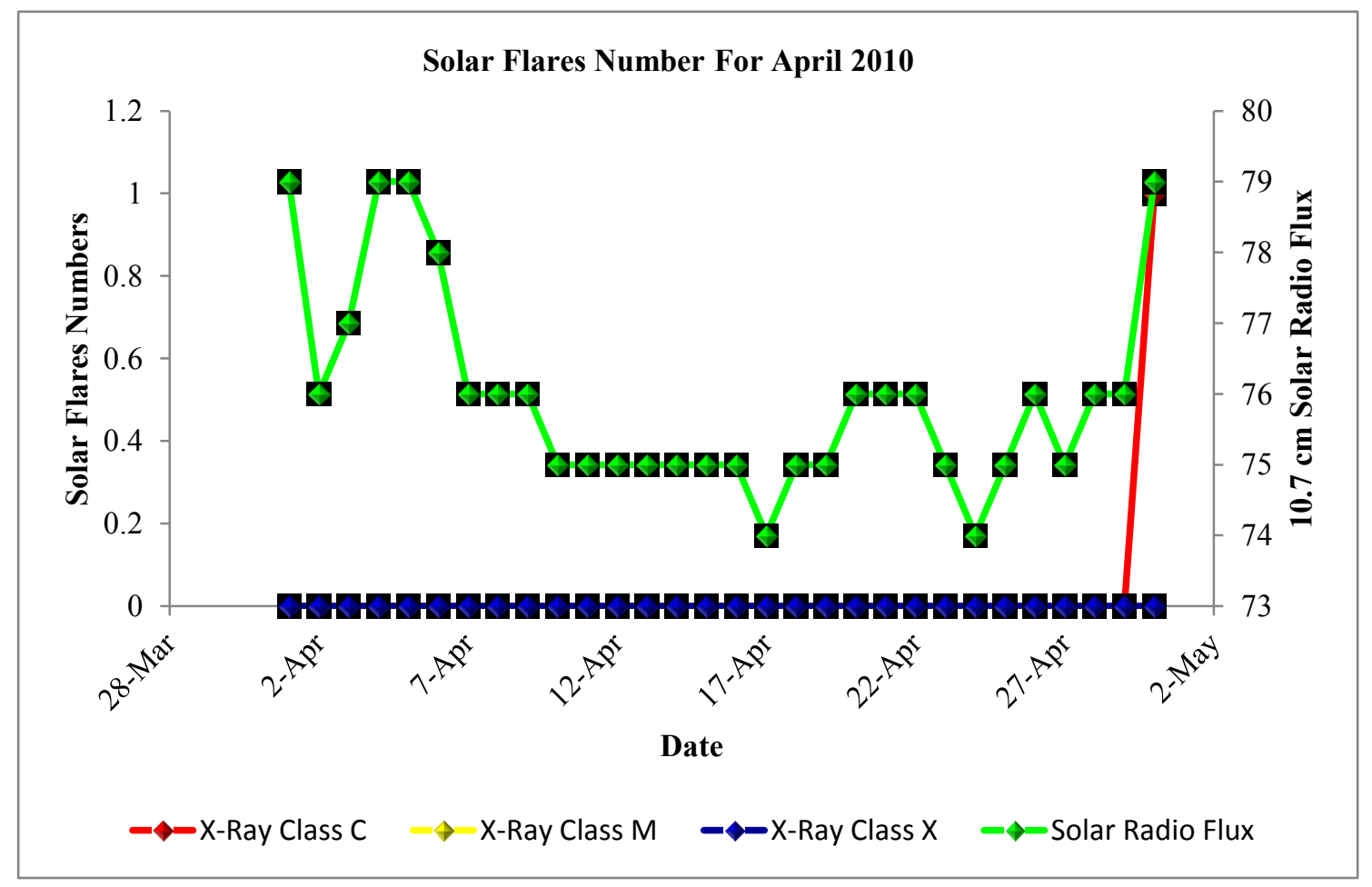

Figure 4. Solar flares numbers in April. 


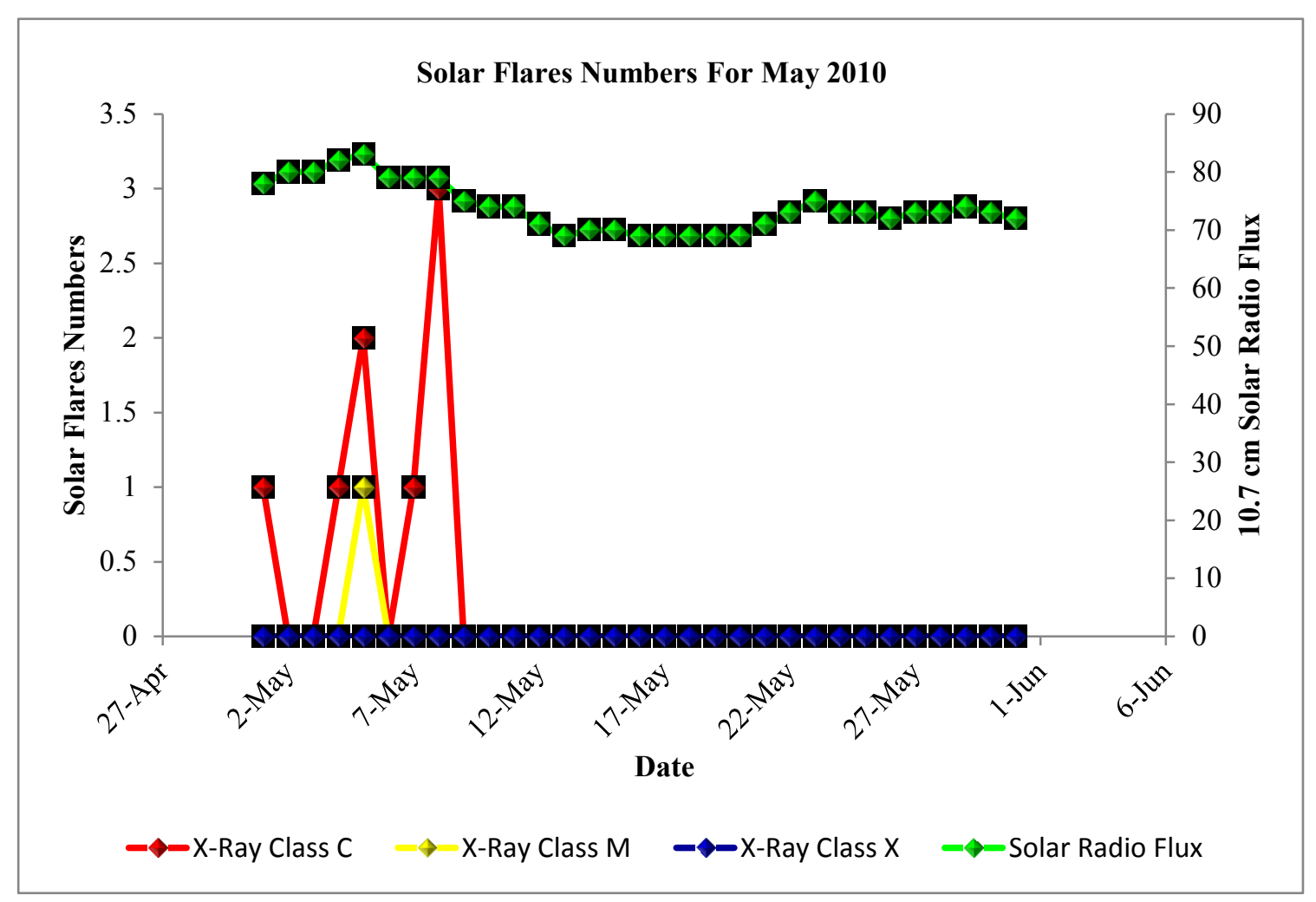

Figure 5. Solar flares numbers in May.

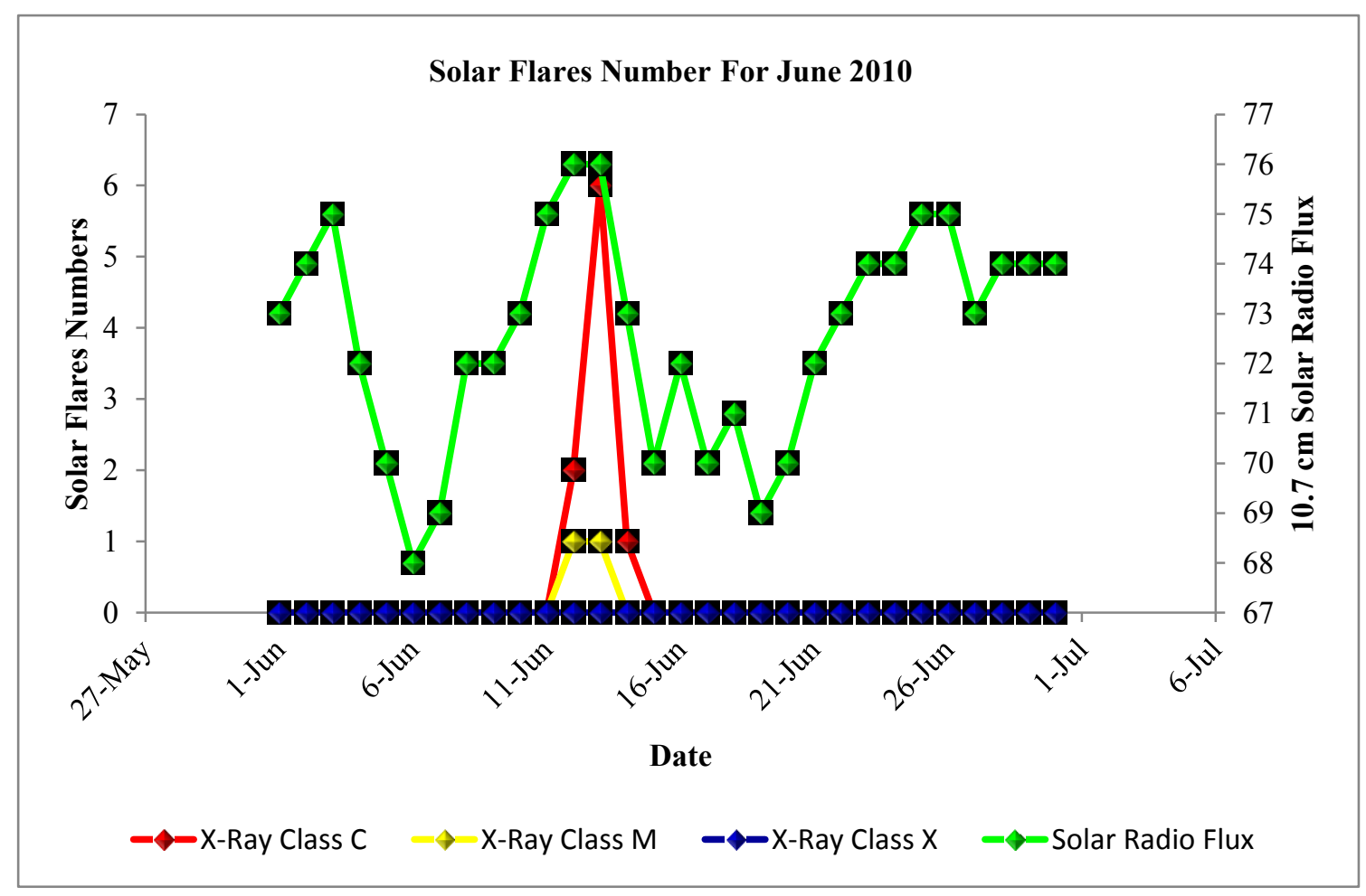

Figure 6. Solar flares numbers in June. 


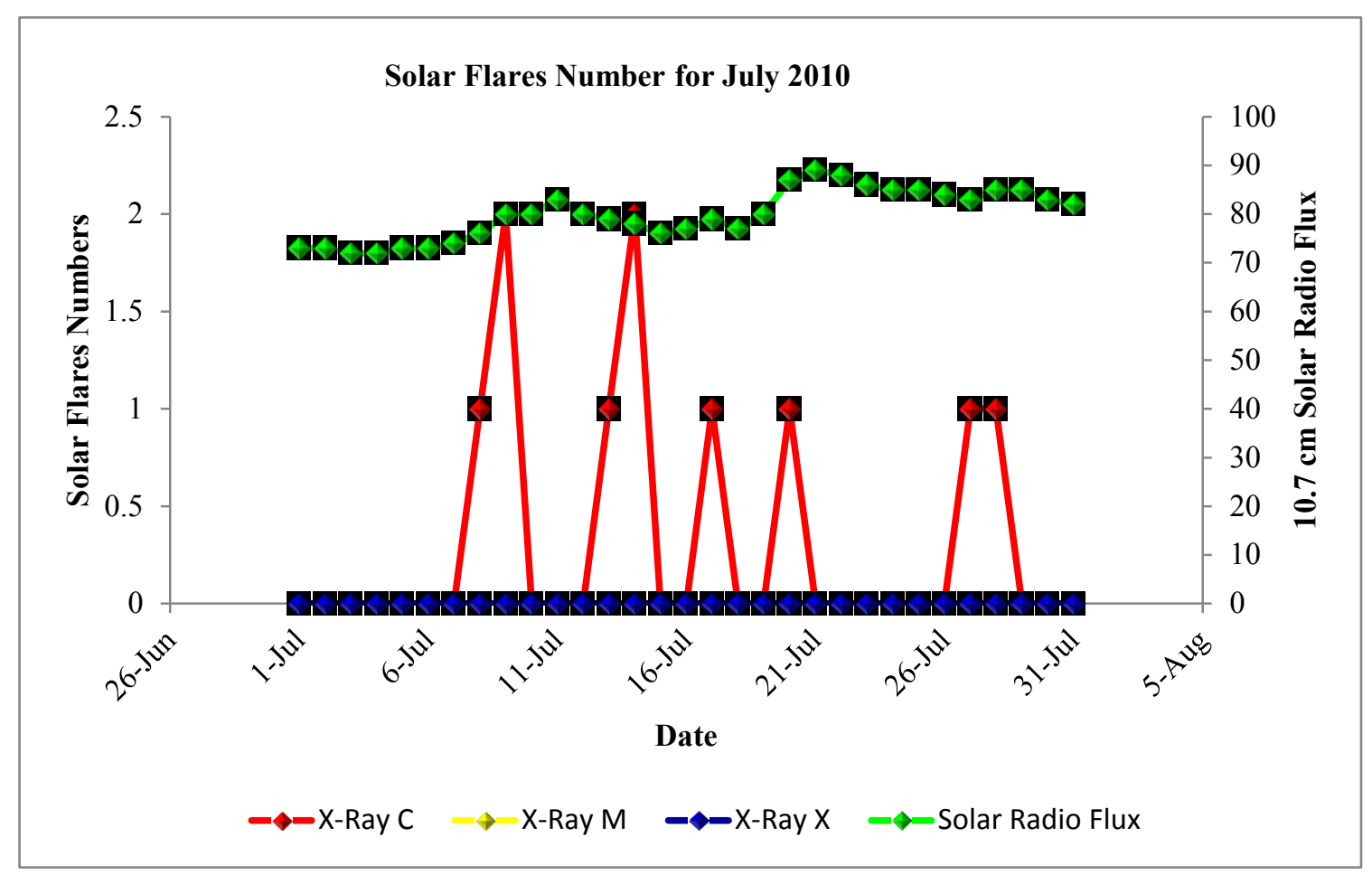

Figure 7. Solar flares numbers in July.

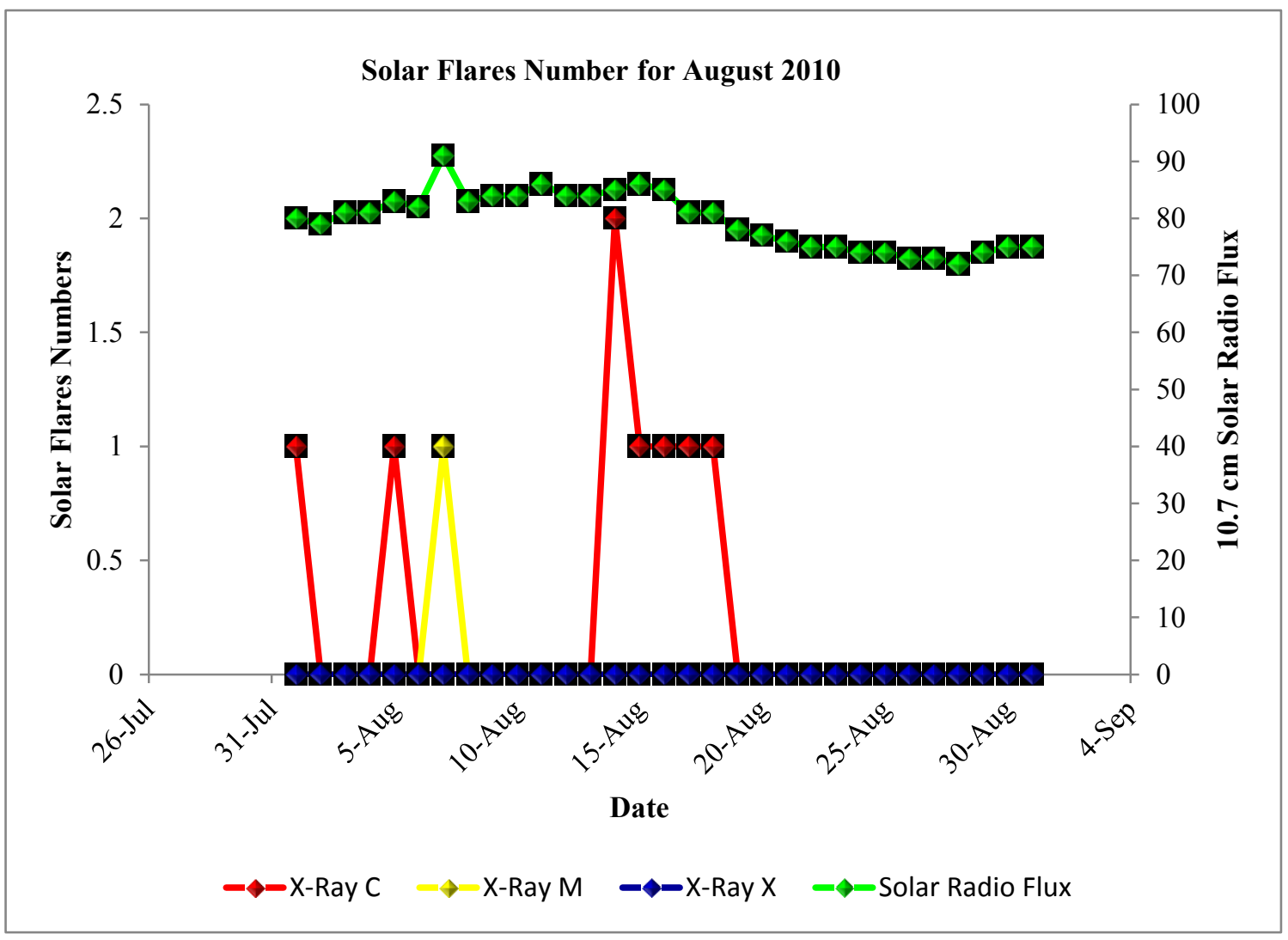

Figure 8. Solar flares numbers in August. 


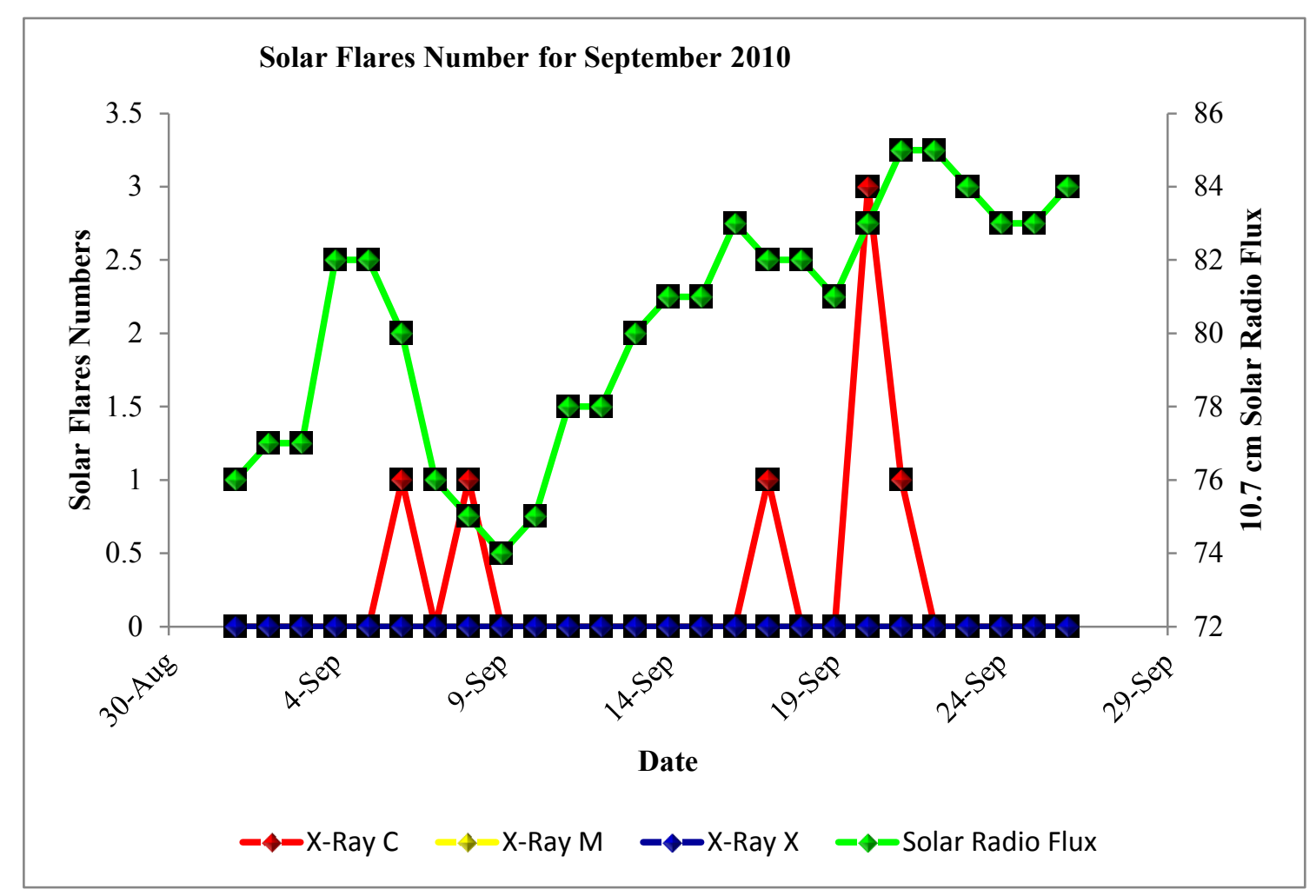

Figure 9. Solar flares numbers in September.

\section{CONCLUDING REMARKS}

As from this study, it was found that there was no solar flare class X produced by the Sun during the period of this study. Resulting from this, we concluded that there are no major effects on earth occurred from January to September. For the recommendation, we should enhance our study comprehensively regarding the solar flares effects. By some means we can at least use the obtained data from the previous observations and pioneer numerous new prediction methods so that we can predict the behavior of the solar flares. For instance, Malaysia which lies on the equator line of the earth should implement various kinds of prediction methods in determining and predicting the upcoming solar flares effects. For a starting point, universities in Malaysia can develop radio telescopes and start monitoring, observing and collecting data from the Sun and develop our very own new prediction methods so that the accuracy of the prediction of the behavior of the sun can be study more precisely.

\section{ACKNOWLEDGEMENT}

We are grateful to CALLISTO network, STEREO, LASCO,SDO/AIA, NOAA and SWPC make their data available online. This work was partially supported by the FRGS (600 RMI/FRGS 5/3 2012) UiTM grants. Special thanks to the National Space Agency and the National Space Centre for giving us a site to set up this project and support this project. Solar burst monitoring is a project of cooperation between the Institute of Astronomy, ETH Zurich, and FHNW Windisch, Switzerland, MARA University of Technology and University of Malaya. This paper also used NOAA Space Weather Prediction Centre (SWPC) for the sunspot, radio flux 
and solar flare data for comparison purpose. The research has made use of the National Space Centre Facility and a part of an initiative of the International Space Weather Initiative (ISWI) program.

\section{BIOGRAPHY}

Dr Zety Sharizat Hamidi is currently a lecturer and focused in Solar Astrophysics research specifically in radio astrophysics at the School of Physics and Material Sciences, Faculty of Sciences, MARA University of Technology, 40450, Shah Alam, Selangor, Malaysia. Involve a project under the International Space Weather Initiative (ISWI) and also a lecturer in School of Physics and Material Science, at MARA University of Technology, Shah Alam Selangor.

C. Monstein is a senior Engineer at Institute of Astronomy, Wolfgang-Pauli-Strasse 27, Building HIT, Floor J, CH-8093 Zurich, Switzerland and one of the researchers who initiated the CALLISTO system around the world.

Dr Nur Nafhatun Md Shariff is a senior lecturer in Academy of Contemporary Islamic Studies (ACIS), MARA University of Technology, 40450, Shah Alam, Selangor, Malaysia.Her current research is more on sustainability; environmental aspect. She is looking forward for cross-field research, i.e. solar astrophysics, light pollution measurement (mapping) and religious studies.

\section{References}

[1] N. M. Vilmer, Energy Conversion and Particle Acceleration in the Solar Corona, Lecture Notes in Physics, Springer, Berlin, 2003.

[2] R. Schwenn, Space Weather: The Solar Perspective, Living Rev. Solar Phys. 3 (2006) 5-54.

[3] M. J. Aschwanden, Güdel, M., ApJ 401 (1992) 736-753.

[4] G. F. Moreton, Astron. J. 69 (1964).

[5] S. M. White, S. Krucker, R. P. Lin, Ap. J. Lett 40 (2007).

[6] A.O. Benz, Flare Observations, Living Rev. Solar Phys. 5 (2008).

[7] Z. S. Hamidi, N. Anim, N. N. M. Shariff, Z. Z. Abidin, Z. A. Ibrahim, C. Monstein, Dynamical structure of solar radio burst type III as evidence of energy of solar flares, in: R.Shukor (Ed.), PERFIK 2012, American Institute of Physics, Malaysia, 2013, pp. 11-15.

[8] Z. Hamidia, Z. Abidina, Z. Ibrahima, N. Shariffa, C. Monsteinc, Observations of Coronal Mass Ejections (CMEs) at Low Frequency Radio Region on 15th April 2012, AIP Conf. Proc 1528 (2013) 55-60.

[9] N. Hashim, Z. Abidin, U. Ibrahim, R. Umar, M. Hassan, Z. Rosli, Z. Hamidi, Z. Ibrahim, Radio Astronomy in Malaysia: Current Status and Outreach Activities, Astronomical Society of the Pacific Conference Series, 2011, pp. 355.

[10] Z. S. Hamidi, Z. Ibrahim, Z. Abidin, M. Maulud, N. Radzin, N. Hamzan, N. Anim, N. Shariff, International Journal of Applied Physics and Mathematics 2 (2011) 3.

[11] Z. S. Hamidi, Z. Z. Abidin, Z. A. Ibrahim, N. N. M. Shariff, U. F. S. U. Ibrahim, R. Umar, Preliminary analysis of investigation Radio Frequency Interference (RFI) profile analysis at Universiti Teknologi MARA, IEEE, 2011, pp. 311-313.

[12] Z. S.Hamidi, S. Chumiran, A. Mohamad, N. Shariff, Z. Ibrahim, N. Radzin, N. Hamzan, N. Anim, A. Alias, American Journal of Modern Physics 2 (2013) 4. 
[13] Z. S. Hamidi, Z. Abidin, Z. Ibrahim, N. Shariff, C. Monstein, International Journal of Engineering Research and Development 3 (2012) 36-39.

[14] Z. S. Hamidi, Z. Abidin, Z. Ibrahim, C. Monstein, N. Shariff, International Journal of Fundamental Physical Sciences 2 (2012) 32-34.

[15] Z. S. Hamidi, N. M. Anim, N. N. S. Hakimi, N. Hamzan, A. Mokhtar, N. Syukri, S. Rohizat, I. Sukma, Z. A. Ibrahim, Z. Z. Abidin, N. N. M. Shariff, C. Monstein, International Journal of Fundamental Physical Sciences 2 (2012) 4.

[16] Z. S. Hamidi, N. N. M. Shariff, International Journal of Science and Mathematics 2 (2014) 3.

[17] Z. S. Hamidi, Z. Abidin, Z. Ibrahim, N. Shariff, Indication of radio frequency interference (RFI) sources for solar burst monitoring in Malaysia, ICPAP 2011, AIP Publisher, Indonesia, 2012, pp. 6.

[18] Z. S. Hamidi, N. N. M. Shariff, C. Monstein, The International Journal of Engineering 1 (2012) 3 .

[19] N. Anim, Z. Hamidi, Z. Abidin, C. Monstein, N. Rohizat, Radio frequency interference affecting type III solar burst observations, 2012 NATIONAL PHYSICS CONFERENCE: (PERFIK 2012), American Institute of Physics, 2013, pp. 82-86.

[20] Z. S. Hamidi, N. N. M. Shariff, R.Umar, Malaysia Thailand Journal of Physics 3 (2012) 6.

[21] Z. S. Hamidi, N. Shariff, Z. Abidin, Z. Ibrahim, C. Monstein, Middle-East Journal of Scientific Research 12 (2012) 6.

[22] Z. S. Hamidi, N. N. M. Shariff, C. Monstein, International Letters of Chemistry, Physics and Astronomy 13(1) (2014) 77-87.

[23] Z. S. Hamidi, N. N. M. Shariff, International Letters of Chemistry, Physics and Astronomy 4 (2014) 29-36.

[24] Z. S. Hamidi, N. N. M. Shariff, International Letters of Chemistry, Physics and Astronomy 5 (2014) 32-42.

[25] Z. S. Hamidi, N. N. M. Shariff, International Letters of Chemistry, Physics and Astronomy 5 (2014) 43-49.

[26] Z. S. Hamidi, N. N. M. Shariff, International Letters of Chemistry, Physics and Astronomy 7 (2014) 21-29.

[27] Z. S. Hamidi, N. N. M. Shariff, International Letters of Chemistry, Physics and Astronomy 7 (2014) 30-36.

[28] Z. S. Hamidi, N. N. M. Shariff, C. Monstein, Z. A. Ibrahim, International Letters of Chemistry, Physics and Astronomy 7 (2014) 37-44.

[29] Z. S. Hamidi, N. N. M. Shariff, C. Monstein, W. N. A. Wan Zulkifli, M. B. Ibrahim, N. S. Arifin, N. A. Amran, International Letters of Chemistry, Physics and Astronomy 8 (2014) 13-19.

[30] Z. S. Hamidi, N. N. M. Shariff, C. Monstein, W. N. A. Wan Zulkifli, M. B. Ibrahim, N. S. Arifin, N. A. Amran, International Letters of Chemistry, Physics and Astronomy 9 (2014) 8-15. 
[31] Z. S. Hamidi, N. N. M. Shariff, M. F. Ali, C. Monstein, W. N. A. Wan Zulkifli, M. B. Ibrahim, N. S. Arifin, N. A. Amran, International Letters of Chemistry, Physics and Astronomy 9 (2014) 84-92.

[32] Z. S. Hamidi, N. N. M. Shariff, C. Monstein, International Letters of Chemistry, Physics and Astronomy 11(1) (2014) 51-58.

[33] Z. S. Hamidi, N. N. M. Shariff, C. Monstein, International Letters of Chemistry, Physics and Astronomy 11(2) (2014) 135-145.

[34] Z. S. Hamidi, N. N. M. Shariff, C. Monstein, International Letters of Chemistry, Physics and Astronomy 11(2) (2014) 167-176.

[35] Z. S. Hamidi, C. Monstein, N. N. M. Shariff, International Letters of Chemistry, Physics and Astronomy 11(3) (2014) 243-256.

[36] Z. S. Hamidi, N. N. M. Shariff, C. Monstein, International Letters of Chemistry, Physics and Astronomy 12 (2014) 84-102.

[37] Z. S. Hamidi, N. N. M. Shariff, C. Monstein, International Letters of Chemistry, Physics and Astronomy 13(2) (2014) 104-111.

[38] Z. S. Hamidi, N. N. M. Shariff, C. Monstein, International Letters of Chemistry, Physics and Astronomy 13(2) (2014) 135-143

[39] Z. S. Hamidi, N. N. M. Shariff, C. Monstein, International Letters of Chemistry, Physics and Astronomy 13(2) (2014) 144-154 